\title{
Research on Tobacco Logistics Delivery Costs Optimization Under the Environment of Information Technology
}

\author{
ZHENG Wenlong ${ }^{1, a}$, ZHANG Shiqing ${ }^{2, b}$ ZHANG Linkai, ${ }^{3, c}$ \\ ${ }^{1,2}$ School of Economageics and Manment, Chang'an University, Xi'an 710064, China; \\ ${ }^{3}$ The Bureau of Land and Resources Kaiyang, Kai Yang550308, China; \\ a534236243@qq.com, ${ }^{\mathrm{b}} 18740477006 @ 163 . c o m,{ }^{\mathrm{c}} 462411213 @ q q . c o m ;$
}

Keywords: Tobacco Industry; Logistics Distrinution costs; Optimization; the Informatization

\begin{abstract}
In recent years, there is more and more debate about adherence and improve the system of tobacco monopoly or abolish tobacco monopoly system. With the increasing competition in the international tobacco market, it makes China's tobacco industry have received the unprecedented challenge. In the face of economic globalization, with the modern advanced information technology to build the tobacco industry logistics, which is the way for the survival and development in the future for China's tobacco industry. And the cost of distribution in tobacco companies occupy large proportion of the total cost of logistics, so we optimize the tobacco company logistics distribution costs based on the information environment. At last, we put forward the model of optimization of fuel management of distribution vehicle.The purpose is to reduce logistics distribution costs of tobacco companies, and improve the market competitiveness.
\end{abstract}

\section{Introduction}

With China entering WTO, the rising of global anti-smoking campaign and the increasing competition in the international tobacco market, it makes China's tobacco industry have received the unprecedented challenge. Under today's condition of exploring the profit is more and more difficult, the potential in the field of logistics is getting more and more attention, logistics field would be a huge "profit source". Although tobacco industry is a "monopoly" system in China, the tobacco companies are in the market economy, it is bound to be affected by the market economy. The research of logistics distribution costs which takes larger proportion in tobacco logistics' total cost, is aimed at reducing the cost andimprovingthe competitiveness of enterprises, the research is imperative. So research of the information distribution system has practical significance for the tobacco companies.

\section{The present situation of modern tobacco logistics in China}

First of all, itlacksthe unified regulationsof basic equipmentin the process of goods transport. Such as the size of the container, the size of the pallet in the container, the size of the truck,the shelves size of tobacco warehouse, these all cannot be matched used.

Second, the standardization of commodity information is lag. Now many of the tobacco companies are setting up their own commodity information database, but the field, type and length of the database are not consistent, this forms a lot of "information lonely islands". The exchange and sharing can't be realized in the inconsistent data, this affects the interface of tobacco logistics enterprise and the outside enterprise, also affects the operation of logistics management and e-commerce.

Finally, the management of logistics standardization is backward. The traditional regional segmentation system makes the tobacco logistics divide into different departments. The lack of effective collaboration between departments leads to cost a lot of time and economic cost in the process of every mode of transportation transport of the transport links, and restricted the rapid development of logistics industry. 


\section{The optimization method of the logistics distribution costs}

Distribution costs refer to the total expenses what happened in the process of distribution.It mainly includes the distribution transportation cost, storage cost, sorting cost, equipping costs and circulation processing cost.Usually the larger cost of tobacco logistics aretwo pieces: storage and delivery.So in order to reduce the total logistics cost of the tobacco companies and enhance its market competitiveness, this paper puts forward a related optimization method to reduce the cost of logistics distribution under the environment of information technology.

The optimization management for tobacco companies to the fuel consumption of distribution vehicle

We can find that fuel management costs in distribution costs accounted for the proportion of larger in tobacco logistics company cost optimization analysis of the situation. It is mainly due to there is noa unified scientific consumption management method for the company.Proposed to use probability estimation algorithm to scientific management to optimize fuel consumption.Through this method to see the consumption level of the company, And by making reasonable consumption quota to manage distribution vehicle fuel consumption optimization of tobacco companies.

\section{The basic principle of probability estimation method}

The method of probability estimation is used in human resource management, we can introduceit into the fuel management optimization process. Probability assessment work is to further improve the experience for quality and reduce the error, and using the method of probability, to improve the accuracy of the assessment work. Probability estimation method is known as the "three valuation method", It is estimated in advance by the management of this company or experts for a working hours, the results are three kinds of numerical: Advanced working hours (To), Conservative working hours (TP), The most likely working hours (TM), then according to the following formula to calculate the advanced and reasonable working hours.

$$
\mathrm{T}=\mathrm{M}+\lambda \sigma
$$

In an expression:

$\mathrm{T}$ - - Process planning

$\mathrm{M}$ - - Average time to process

$\lambda$ _

$\sigma$ —- Standard deviation of working hours of normal distribution

Among them:

$$
M=\frac{T_{o}+4 T_{p}+T_{m}}{6} \sigma=\frac{T_{p}-T_{o}}{6}
$$

2. 1. 2The management optimization for vehicle fuel consumption

Application the principle of probability estimation method in the fuel management optimization, the optimization steps can be as follows:

(1) Statistical analysis is carried out on the thyme oil consumption situation

(2) Application probability estimation method for the optimization

According to the principle of probability estimation method,takethe thyme oil consumption into probability estimation, as follows:

a----Advanced consumption (the consumption under the most favorable conditions.)

b----Conservative consumption (the consumption under the most unfavorable conditions.)

c----Normal consumption

We get the above three conditions of fuel consumption value, through the analysis of the consumption data and estimates of most experienced staff.

Application of probability estimation method to calculate:

According to a, b, c three kinds of fuel consumption value, and obtainits average fuel consumption $\mathrm{M}$

average valueM= $(\mathrm{a}+4 \mathrm{~b}+\mathrm{c}) / 6$ 
Due to there is a certain gap in quarter consumption, it is discrete degree, $\sigma$ 2express discrete, $\sigma$ express the standard deviation

$$
\sigma^{2}=[(\mathrm{b}-\mathrm{a}) / 6] 2 \sigma=(\mathrm{b}-\mathrm{a}) / 6
$$

$\sigma$ :Its size reflects the size of the discrete degree.Its discrete degree is smaller, it is more representative, the representative smaller conversely.Its size is related tothe quantity of smoke transportation and the order from sell smoke point in the quarter. The sales of cigarettes has to do with seasons, Then it reflects the fluctuation of smoke volume volatility in the quarter.The computation formula is as follows:

$$
\begin{aligned}
& \mathrm{P}=\mathrm{M}+\lambda \sigma \\
& \text { Among them, } \\
& \mathrm{P} \_ \text {- Fuel consumption quota plan in quarter; } \\
& \lambda \_ \text {_ probability coefficient } \\
& \text { Among them: } \\
& \lambda \text { values can be seen in normal distribution table } \\
& \mathrm{P}(\lambda) \text {, See the table below: }
\end{aligned}
$$

\section{Among them:}

Table2-1-2

\begin{tabular}{cccccccc}
\hline$\lambda$ & $\mathrm{P}(\lambda)$ & $\lambda$ & $\mathrm{P}(\lambda)$ & $\lambda$ & $\mathrm{P}(\lambda)$ & $\lambda$ & $\mathrm{P}(\lambda)$ \\
\hline-0.0 & 0.50 & -1.3 & 0.10 & 0.0 & 0.50 & 1.3 & 0.90 \\
-0.1 & 0.46 & -1.4 & 0.08 & 0.1 & 0.54 & 1.4 & 0.92 \\
-0.2 & 0.42 & -1.5 & 0.07 & 0.2 & 0.58 & 1.5 & 0.93 \\
-0.3 & 0.38 & -1.6 & 0.05 & 0.3 & 0.62 & 1.6 & 0.95 \\
-0.4 & 0.34 & -1.7 & 0.04 & 0.4 & 0.66 & 1.7 & 0.96 \\
-0.5 & 0.31 & -1.8 & 0.04 & 0.5 & 0.69 & 1.8 & 0.96 \\
-0.6 & 0.27 & -1.9 & 0.03 & 0.6 & 0.73 & 1.9 & 0.97 \\
-0.7 & 0.24 & -2.0 & 0.02 & 0.7 & 0.76 & 2.0 & 0.98 \\
-0.8 & 0.21 & -2.1 & 0.02 & 0.8 & 0.79 & 2.1 & 0.98 \\
-0.9 & 0.18 & -2.2 & 0.01 & 0.9 & 0.82 & 2.2 & 0.99 \\
-1.0 & 0.16 & -2.3 & 0.01 & 1.0 & 0.84 & 2.3 & 0.99 \\
-1.1 & 0.14 & -2.4 & 0.01 & 1.1 & 0.86 & 2.4 & 0.99 \\
-1.2 & 0.12 & -2.5 & 0.01 & 1.2 & 0.88 & 2.5 & 0.99
\end{tabular}

Using this method we can estimate vehicle fuel consumption level for the distribution truck of tobacco companies,and according to previous data, we can also formulate a scientific and reasonable consumption standards for the company. At present, there is no a scientific and reasonable standard for many tobacco companies to manage fuel consumption. So it is feasible for tobacco companies to reduce distribution costs through fuel consumption cost management to establish a reasonable consumption value.

\section{Conclusion}

In the information environment, due to the driving of logistics business, the information system can integrate and schedule all kinds of distribution resources,(such as: homework personnel, equipment, vehicles, etc.), establish harmonious and complete logistics system, provides favorable conditions for route optimization and fuel consumption optimization.Under the environment of information, this paper providesthe optimization method distribution vehicle fuel management for 
tobacco companies, it can not only help the tobacco companies to reduce the logistics cost, but also help to enhance the market competition ability of tobacco companies. The optimization model given by this paper, which is access to get information and easy to operation. When we apply papers results, the simple fast procedure and software can be developed to reduce the workload and improve work efficiency for the tobacco companies.

\section{References}

[1] Fu Jingyan, TangHuankunThe development trend of international logistics industry and the countermeasures of our country[J]. Logistics technology, 2003(3): 26-28

[2] Li Baojiang, JiangHonghai, HengBingquan. During the financial crisis on the global tobacco development momentum[J]. China tobacco, 2009(17): 67-70

[3] WangXiaoyun. Try to discussabout the necessity of logistics information[J]Railway supplies scientific management, 2003(3)

[4] Zhang Zhengyi, ZhengXiaohai, ZhangYongzheng The overview of tobacco business of modern logistics development in China [J]Logistics technology\&Application， 2006 (2)

[5] Wu JianrongThe construction of the tobacco commercial enterprise logistics system[J]. China Tobacco Society 2004 academic essays

[6] Bi XiaonaInformatizationmission of tobacco logistics[J]. China Logistics \& Purchasing , 2007(3) 